\title{
Pulmonary Pathology of Erdheim-Chester Disease
}

Walter L. Rush, M.D., Jo Ann W. Andriko, Lt.C., M.C., U.S.A., Francoise Galateau-Salle, M.D., Elizabeth Brambilla, M.D., Christian Brambilla, M.D., I. Ziany-bey, M.D., Melissa L. Rosado-de-Christenson, Col., U.S.A.F., M.C., William D. Travis, M.D.

Departments of Dermatopathology (WLR) and Hematopathology (JAWA), Armed Forces Institute of Pathology, Washington, D.C.; University de Caen (FG-S) and Centre Hospitalier Universitaire de Grenoble (EB, CB, IZ-b), France; and Departments of Radiologic Pathology (MLR-d-C) and Pulmonary and Mediastinal Pathology (WDT), Armed Forces Institute of Pathology, Washington, D.C.

Erdheim-Chester disease (ECD) is a rare nonLangerhans' cell histiocytosis that may present with pulmonary symptoms. The condition seems to be nonfamilial and typically affects middle-aged adults. Radiographic and pathologic changes in the long bones are diagnostic, but patients often present with extraskeletal manifestations. Advanced pulmonary lesions are associated with extensive fibrosis that may lead to cardiorespiratory failure. The clinical, radiologic, and pathologic features of six patients with ECD with lung involvement are presented. The patients were three men and three women (mean age, 57). Five presented with progressive dyspnea, and one presented with diabetes insipidus. Open-lung biopsies showed histiocytic infiltrates in a lymphangitic pattern with associated fibrosis and lymphoplasmacytic inflammatory infiltrates. The histiocytes did not stain with periodic acid-Schiff. Immunoperoxidase studies performed on specimens from five of six patients showed that the histiocytes were positive for CD68 and Factor XIIIa and negative for CD1a. Specimens from two patients exhibited immunoreactivity for S-100 protein. Electron microscopy studies performed on specimens from two patients showed phagocytic lysosomes but no Birbeck granules. Clinical follow-up of up to $\mathbf{1 6}$ years was available. At the end of that time, five patients were dead of complications related to their disease; one patient remains alive 4 years after diagnosis but with severe respiratory compromise. ECD is a rare nonLangerhans' cell histiocytosis that may present as

Copyright (C) 2000 by The United States and Canadian Academy of Pathology, Inc.

VOL. 13, NO. 6, P. 747, 2000 Printed in the U.S.A.

Date of acceptance: January 10, 2000.

The opinions and assertions contained herein are the private views of the authors and are not to be construed as official or as representing the views of the Departments of Defense, the Air Force, or the Army.

Address reprint requests to: Walter L. Rush, M.D., Department of Dermatopathology, Armed Forces Institute of Pathology, Washington, DC 20306-6000; fax: 202-782-3075. interstitial lung disease and resemble other pulmonary conditions, particularly usual interstitial pneumonitis and pulmonary Langerhans' cell histiocytosis. Recognition of this entity will allow better assessment of its true incidence, therapeutic options, and prognosis.

KEY WORDS: Erdheim-Chester disease, Factor XIIIa, Histiocytosis, Lung.

Mod Pathol 2000;13(6):747-754

In 1930, while doing a fellowship with the pathologist Jakob Erdheim (1874-1937), the American physician (future cardiologist) William Chester (19031974) published the clinical and pathologic findings of two patients who he believed had a distinctive lipidosis not previously described (1). In 1972, Jaffe reviewed the findings of Chester's original patients along with those of a patient published by Sorenson (2) and reported on a fourth patient of his own. He postulated that the four patients represented the same histiocytic disorder and coined the eponym Erdheim-Chester disease (ECD) (3).

ECD is a rare non-Langerhans' cell histiocytosis characterized by symmetrical sclerosis involving the diametaphyseal aspects of the long bones. Radiographically, these findings are considered virtually pathognomonic. Nonosseous disease is also well recognized and includes hypothalamus/pituitary involvement with resultant diabetes insipidus, renal and retroperitoneal infiltration, and xanthoma-like skin lesions, particularly on the eyelids (4). Similar to Langerhans' cell histiocytosis, the clinical course of ECD varies and is dependent on the extent and distribution of extraosseous disease. Although lung involvement is uncommon, pulmonary fibrosis plays a significant role in the disease's overall morbidity and mortality.

The majority of the published reports on ECD have focused on radiologic, orthopedic, orbital, and central nervous system manifestations. Documen- 
tation of the pulmonary pathology is limited to case reports of ECD $(1,5-13)$ and a single series (14). In an extensive review of the literature, Veyssier-Belot et al. (4) found that 8 of 59 (14\%) reported patients had radiographic evidence of pulmonary involvement with respiratory and cardiac failure, the most common causes of death. Herein, we describe the clinical and pathologic features of six patients of ECD with lung involvement and discuss the relationship of ECD to other histiocytic disorders.

\section{MATERIALS AND METHODS}

We reviewed the records six patients who had ECD with lung involvement, which were collected for study of the pulmonary manifestations of the disease. Diagnostic criteria included a consistent clinical presentation, supportive radiographic data, a fibrohistiocytic infiltrate on biopsy, and absence of Birbeck granules or of CDla expression as detected by immunohistochemical techniques. Although radiographic data concerning the long bones for Patient 2 were not characteristic of ECD, this patient was included because the clinical presentation of pulmonary symptoms occurred 2 years after the long bone radiographs were made and because the clinical presentation, histopathology, and immunohistochemical profile were convincingly persuasive.

Four patients were diagnosed at the Armed Forces Institute of Pathology, and our French colleagues (FG-S, EB) contributed the material on two patients. Patient 4 was previously reported with emphasis on the clinical aspects (15). The orbital features of Patients 5 and 6 were likewise previously reported (16). Hematoxylin and eosin-stained slides, paraffin-embedded tissue blocks, and a clinical history were available for each patient. Chest radiographs, CT scans, or radiologic reports were also available for each patient. Bone biopsies (Patients 2 and 5) or a pathology report (Patient 1) was available for three patients. In addition, a bone marrow biopsy specimen (Patient 6) or a pathology report (Patient 3) was available for two patients. Autopsy material from three patients $(3,5$, and 6$)$ was also examined.

Specimens from each patient were evaluated with a periodic acid-Schiff stain. Immunoperoxidase stains for S-100 protein (Dako, Carpinteria, CA; 1:800), CD1a (Diatech Diagnostics, Inc., Allston, MA; 1:20), CD 68 (Dako; 1:200), LCA (Dako; 1:50), keratin cocktail (ae1/ae3 + ck1; Roche Diagnostics, Indianapolis, IN, 1:400 and Dako, 1:2), EMA (Dako; 1:800), Factor XIIIa (Calbiochem, La Jolla, CA; 1:2000), and CD21 (Dako, 1:50) were performed on specimen sections from each patient using the avidin-biotin-peroxidase technique of $\mathrm{Hsu}$ and Raine (17). The tissue sections were treated with $0.4 \%$ pepsin in $0.01 \mathrm{~N} \mathrm{HCl}$ for $15 \mathrm{~min}$ at $37^{\circ} \mathrm{C}$. Endogenous peroxidase activity was suppressed by treatment with $3 \%$ hydrogen peroxide in methanol for $15 \mathrm{~min}$ at room temperature. This was followed by incubation overnight at room temperature, formation of the ABC complex (Vector elite kit; Vector Laboratories, Burlingame, CA), and development of the color with diaminobenzidine tetrahydrochloride (3,3'-diaminobenzidine). Electron microscopic studies were performed on specimens from $\mathrm{Pa}$ tients 1 and 4 .

\section{RESULTS}

\section{Clinical Findings}

There were three men and three women whose ages ranged from 34 to 71 years (mean, 57) at the onset of symptoms (Table 1). All patients were Caucasian. Three had known inhalational tobacco use,

TABLE 1. Clinical Features of Erdheim-Chester Patients

\begin{tabular}{|c|c|c|c|c|}
\hline Patient & Demographic & Presentation & Past Medical History & Clinical Course \\
\hline 1 & $71 \mathrm{CM}$ & $\begin{array}{l}\text { Dyspnea, } 10-\mathrm{kg} \text { weight loss, fatigue, } \\
\text { migratory bone pain, anemia }\end{array}$ & $\begin{array}{r}\text { Nonsmoker, CAD, HTN, } \\
\text { hypercholesterolemia }\end{array}$ & $\begin{array}{l}\text { Death due to respiratory failure } 5 \mathrm{y} \\
\text { after presentation }\end{array}$ \\
\hline 2 & $63 \mathrm{CM}$ & $\begin{array}{l}\text { Dyspnea and dry cough of several } \\
\text { weeks' duration, weakness, fatigue }\end{array}$ & $\begin{array}{l}\text { Former smoker, HTN, } \\
\text { peripheral vascular disease }\end{array}$ & $\begin{array}{l}\text { Death } 2 \text { mo after initial presentation } \\
\text { due to respiratory failure, } \\
\text { pneumonia }\end{array}$ \\
\hline 3 & $69 \mathrm{CF}$ & $\begin{array}{l}\text { Progressive dyspnea, anemia, } 16 \text { mo } \\
\text { FUO with leucocytosis }\end{array}$ & $\begin{array}{l}\text { Nonsmoker, severe CAD, } \\
\text { bivalvular incompetence, } \\
\text { hypercholesterolemia, } \\
\text { HTN }\end{array}$ & $\begin{array}{l}\text { Death due to acute oliguric renal } \\
\text { failure } 1 \text { mo after presentation }\end{array}$ \\
\hline 4 & $41 \mathrm{CF}$ & $\begin{array}{l}3 \text { y insidious dyspnea, } 2 \text { mo bilateral } \\
\text { leg pain }\end{array}$ & unremarkable & $\begin{array}{l}\text { Alive } 3 \text { y after presentation with } \\
\text { declining respiratory status }\end{array}$ \\
\hline 5 & $40 \mathrm{CF}$ & $\begin{array}{l}\text { Bilateral leg pain followed } 2 \text { y later } \\
\text { by bilateral proptosis and } \\
\text { periorbital xanthomas }\end{array}$ & $\begin{array}{l}\text { "Light" smoker with 6-y } \\
\text { history of diabetes } \\
\text { insipidus, labile HTN }\end{array}$ & $\begin{array}{l}\text { Death } 16 \text { y after diabetes insipidus } \\
\text { onset due to cerebrovascular } \\
\text { accident and coma, renal failure }\end{array}$ \\
\hline 6 & $65 \mathrm{CM}$ & $\begin{array}{l}\text { Progressive dyspnea, 9-kg weight } \\
\text { loss, followed in } 4 \text { y by proptosis, } \\
\text { periorbital xanthomas, } \\
\text { hepatosplenomegaly }\end{array}$ & unremarkable & $\begin{array}{l}\text { Death } 9 \text { y after presentation due to } \\
\text { right-sided heart failure secondary } \\
\text { to lung fibrosis, pulmonary } \\
\text { embolism }\end{array}$ \\
\hline
\end{tabular}

FUO, fever of unknown origin; CAD, coronary artery disease; HTN, hypertension. 
one denied such exposure, and the status of the remaining two patients is unknown. Five patients presented with dyspnea with variable constitutional symptoms. One patient (Patient 5) had a 6-year history of diabetes insipidus before presentation with leg pains. This patient and one other (Patient 6) developed proptosis and periorbital xanthomas at intervals of 2 and 4 years after presentation, respectively. These same two patients developed mild diabetes mellitus late in their disease. Musculoskeletal symptoms including bilateral leg pain occurred in three patients $(1,4$, and 5$)$.

\section{Laboratory Findings}

At the time of diagnosis, anemia was present in four of six patients with total hemoglobins ranging from 9.5 to $10.2 \mathrm{~g} / \mathrm{dL}$ (normal, 14.6 to $17.8 \mathrm{~g} / \mathrm{dL}$ ). Patients 4 and 6 had hemoglobin and hematocrits in the normal range. Two patients had a leucocy- tosis. Patient 3 developed leucocytosis (white blood cell count, $34,000 / \mathrm{mm}^{3}$ with $28 \%$ bands) and fever of unknown origin, both of which had been present for 16 months before diagnosis. Patient 6 had a white blood cell count of $14,900 / \mathrm{mm}^{3}$.

\section{Radiographic Findings}

In each case, the chest radiograph showed varying degrees of increased interstitial markings as well as pleural thickening (Fig. 1). The chest radiographs of Patient 2 also showed bullous changes and cystic lesions bilaterally as well as cardiac enlargement. Two patients (3 and 6) had radiographic evidence of cardiac enlargement and pleural effusions. In addition, Patient 1 had CT scans of the chest that showed widespread smooth thickening of the interlobular septa (Fig. 1). The CT scan of this patient also demonstrates sclerotic lesions of the thoracic vertebrae.
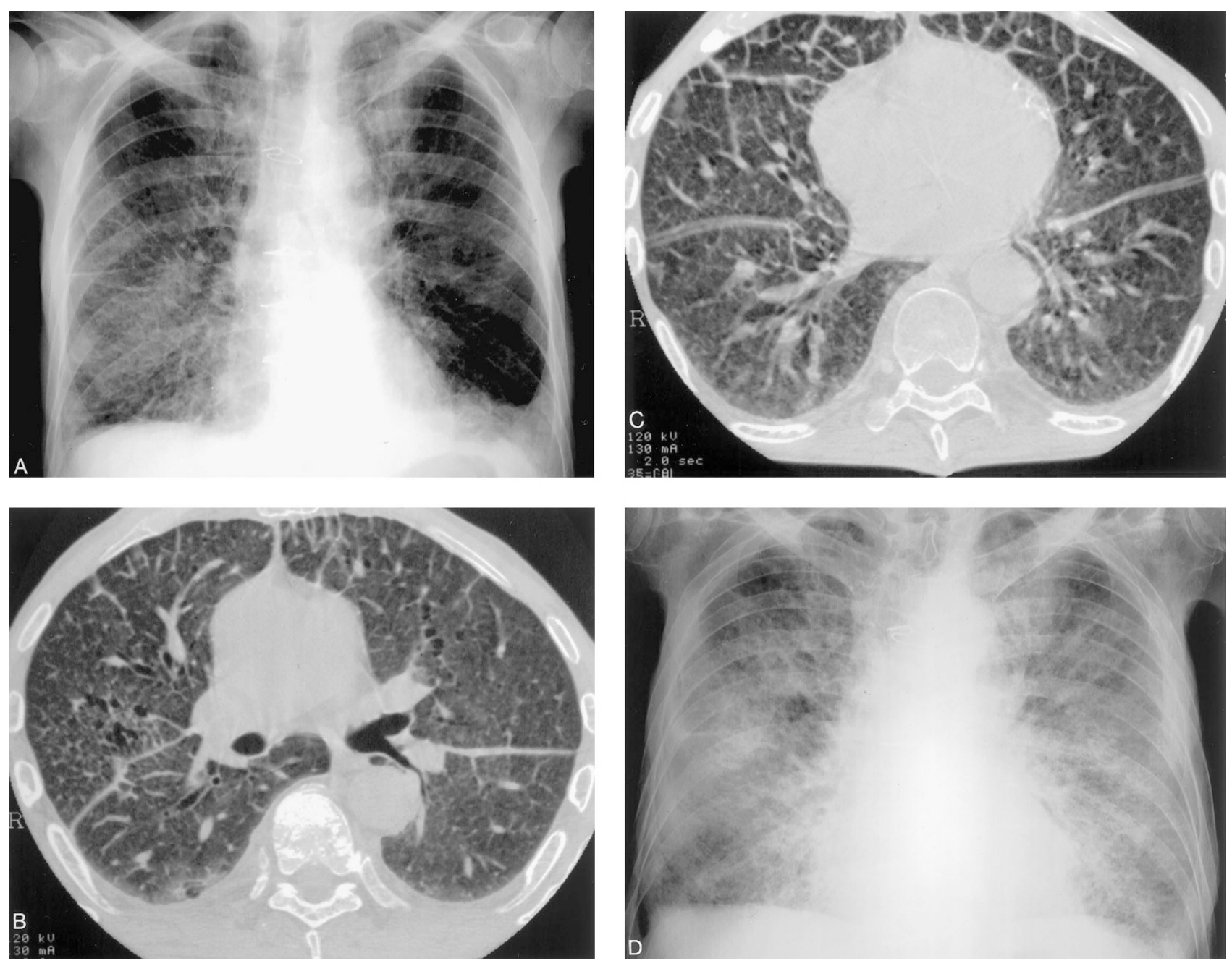

FIGURE 1. Patient 1. A, Posteroanterior chest radiograph demonstrating diffuse bilateral interstitial opacities. There is evidence of prior sternotomy and pleural thickening and/or fluid of unknown chronicity. B, C, high-resolution CT scan of the lung demonstrating diffuse bilateral smooth thickening of the interlobular septa throughout the lung. Foci of cystic lung disease are present in the mid-right lung. There is also thickening of the fissures. Note the osseous sclerosis of the vertebral body in B. D, Posteroanterior chest radiograph obtained 5 years after the image in A demonstrating marked progression of interstitial lung disease and increased pleural thickening. 
For each patient (except Patient 2), skeletal radiographs showed symmetrical sclerotic or mixed sclerotic/lytic lesions of the metaphyseal and diaphyseal regions. For Patient 2, perioperative radiographs of the right lower extremity were made 2 years before presentation with pulmonary symptoms. At that time, the patient underwent a right-sided above-the-knee amputation because of an aneurysm and occlusion of the right popliteal artery. The films showed bone resorption and some features suggesting the possibility of Paget's disease.

Abdominal CT scans were available for three patients. For Patient 2, the scan demonstrated mild splenic enlargement $(15 \mathrm{~cm})$. Abdominal CTs in Patients 3 and 5 showed perinephric retroperitoneal fibrosis, which resulted in bilateral hydronephrosis. Orbital CT scans of Patients 5 and 6 each showed large, symmetrical, homogeneous, dense, enhancing soft tissue masses filling the muscle cones of both orbits.

\section{Histologic Features}

Five patients underwent wedge biopsies of the lung. The sections from Patient 5 were obtained at autopsy. Patients 3 and 6 also underwent autopsy. Low-power appearance in the specimens from the five patients in which antemortem biopsies were available were similar to one another and showed marked thickening and fibrosis of the interlobular septa and perivascular interstitium (Figs. 2 and 3) with lesser involvement of the peribronchiolar areas (Fig. 4). Within each area of fibrosis, there was a proliferation of large histiocytes with round to oval nuclei and moderate to abundant cytoplasm that varied form lightly eosinophilic to pale staining or foamy cytoplasm (Fig. 5). The pleura was likewise markedly thickened by a histiocytic infiltrate with fibrosis. Multinucleated giant cells were prominent

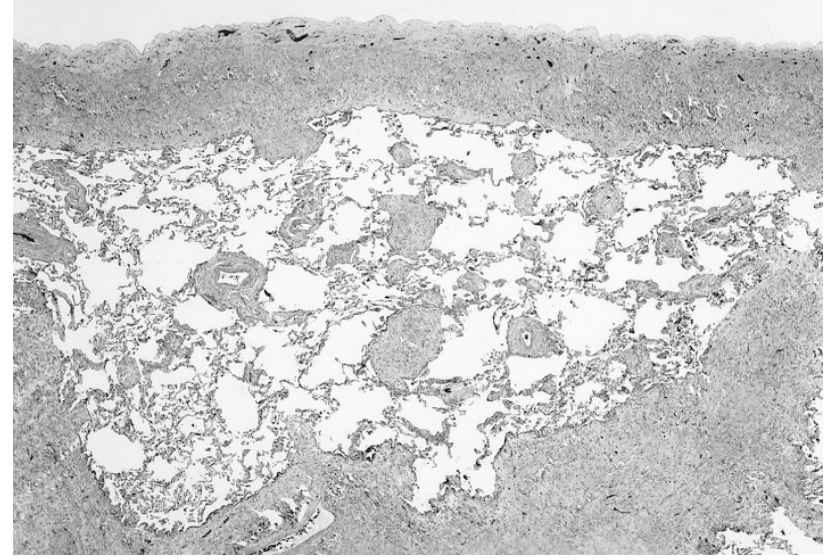

FIGURE 2. Patient 2. Lung. The pleura, septa, and perivascular adventitia are thickened by a fibro-histiocytic infiltrate $(7.5 \times)$.

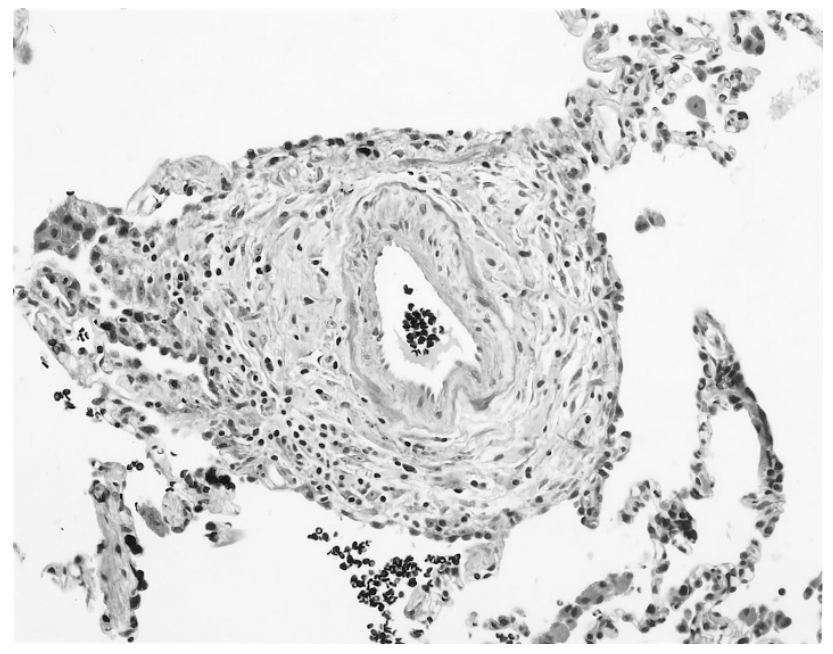

FIGURE 3. Patient 1. Lung. Higher magnification of perivascular infiltrate $(200 \times)$.

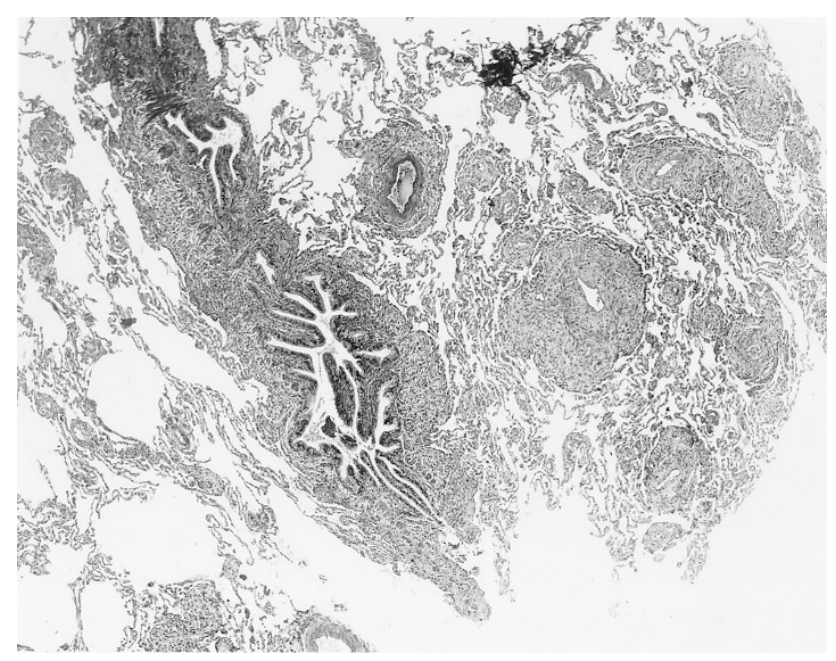

FIGURE 4. Patient 1. Lung. There is a prominent peribronchial and perivascular fibrohistiocytic infiltrate $(30 \times)$.

in specimen sections from Patient 1 , particularly in the pleura (Fig. 6). Postmortem sections of lung from Patient 5 showed much less fibrosis than that seen in the specimens from the other patients, but the distribution and presence of large histiocytic cells were the same. Emperipolesis was not identified. Accompanying the histiocytic proliferation were variable infiltrates of small lymphocytes, plasma cells, and, in Patient 1, rare eosinophils.

Bone biopsies from the long bones of Patients 1 and 5 showed varying degrees of trabecular thickening and partial replacement of the marrow by fibrohistiocytic infiltrates. A bone marrow biopsy taken from Patient 2 as part of an evaulation for anemia at the time of presentation with pulmonary symptoms showed similar histology as the bone biopsies taken from Patients 1 and 5 (Fig. 7). Morphologically diagnostic features of Paget's disease that had been suggested on the earlier radiographs 


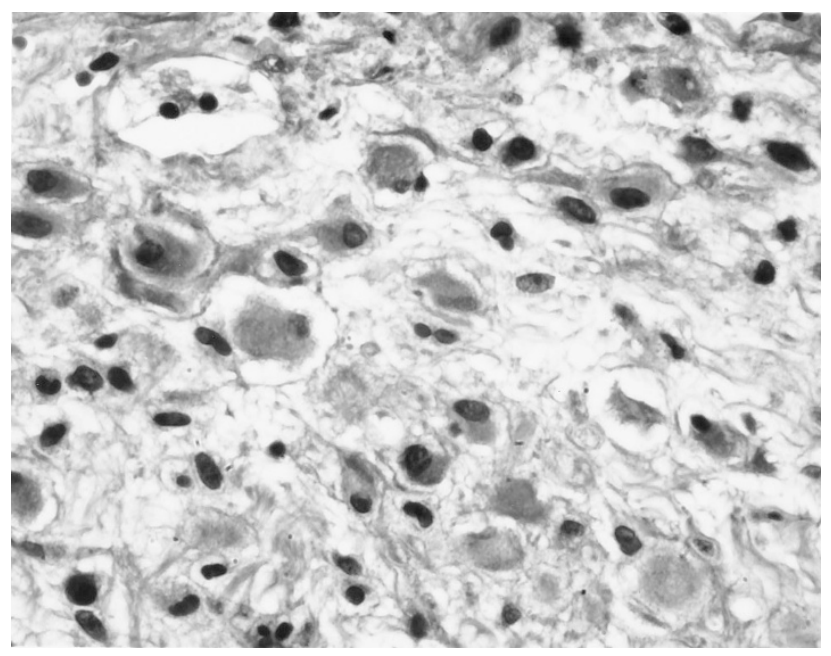

FIGURE 5. Patient 1. Lung. High magnification showing proliferation of large histiocytes with round to oval nuclei and abundant cytoplasm. The cells are surrounded by fibrosis $(600 \times)$.

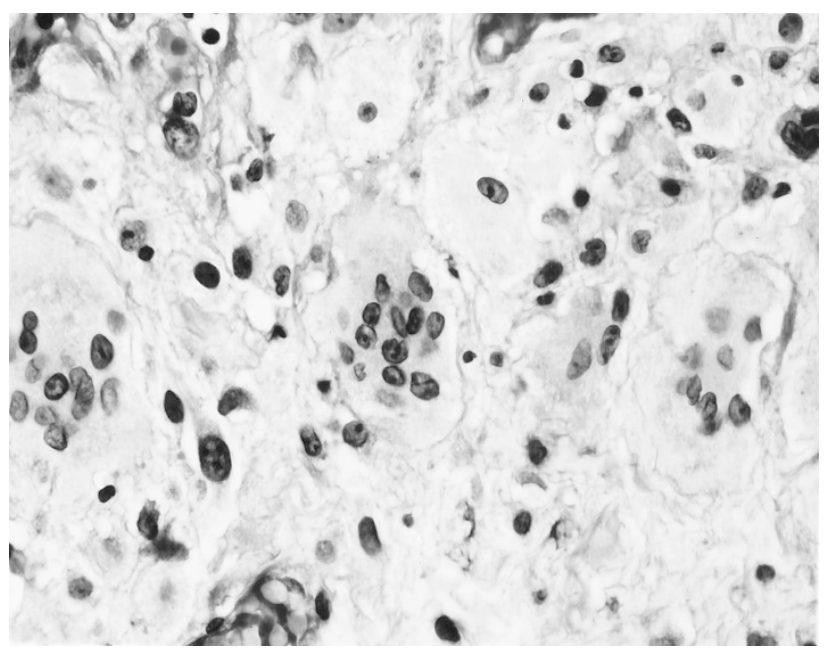

FIGURE 6. Patient 1. Pleura. High magnification of thickened pleura showing numerous multinucleated giant cells admixed with mononuclear histiocytes with abundant pale-staining or foamy cytoplasm $(600 \times)$.

of Patient 2 were not identified. Patient 5 also had lumbar vertebral sections taken at postmortem that showed similar findings as the previous long bone biopsy. Iliac crest bone marrow biopsies from $\mathrm{Pa}-$ tients 3 and 6 were normocellular without involvement by fibrohistiocytic infiltrates.

Retroperitoneal involvement in Patients 3 and 5 led to renal failure. Biopsy of a right perinephric mass from Patient 3 showed infiltrates of foamy histiocytes, consistent with ECD. Autopsy specimens of Patients 3, 5, and 6 demonstrated widespread multisystem involvement. Of particular interest, in Patient 5 was the pericardial and great vessel envelopment by a xanthogranulomatous mass that tracked along the coronaries as well as the aortic root, arch, and proximal descending aorta. The mass enveloped both carotid arteries

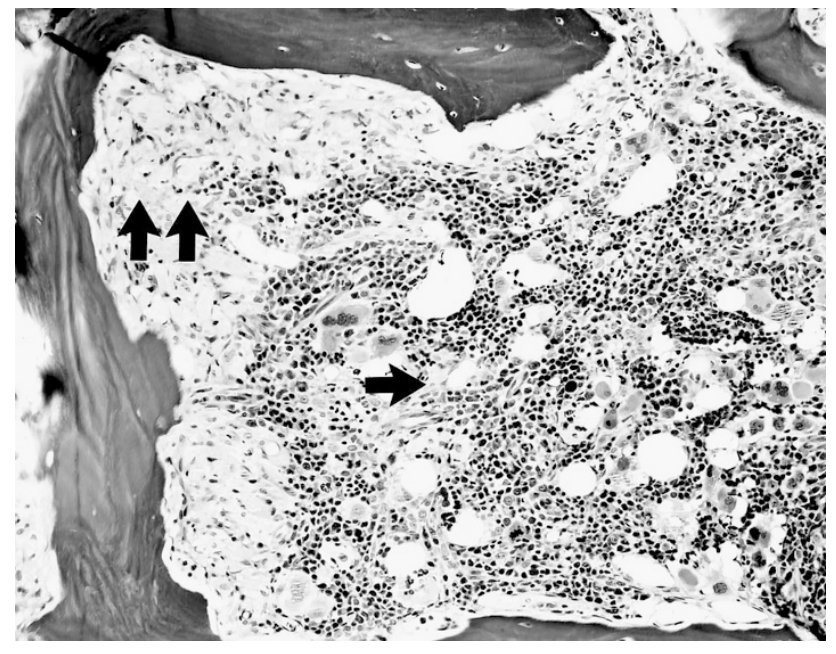

FIGURE 7. Patient 2. Long bone biopsy. The trabeculae are thickened. There are remnant marrow elements (single arrow) and a diffuse paratrabecular fibrohistiocytic infiltrate (double arrow) (150×).

and extended cephalad into the neck. Both of these arteries showed evidence of compression. The compression was nearly complete on the left side.

\section{Histochemical and Immunohistochemical Findings}

Periodic acid-Schiff-stained sections were negative in each case. Immunoperoxidase studies (Table 2 ), performed in five cases, demonstrated strong positivity for CD68 and Factor XIIIa in the histiocytes in each case (Fig. 8). S-100 protein was positive in two cases. Weak staining for lysozyme was also noted in two cases. Other stains, including CD1a, CD45RB, CD21, and keratin, were negative in all cases. Immunoperoxidase studies on the bone marrow specimen of Patient 2 were positive for CD68, Factor XIIIa, and S-100 protein but negative for CDla.

\section{Ultrastructural Findings}

For the two patients ( 1 and 4 ) whose tissue specimens were submitted for electron microscopy studies, no Birbeck granules were identified. Histiocytic cells in each of these cases showed scant quantities of lipid in phagolysosomes.

\section{Clinical Follow-Up}

Clinical follow-up was available for all patients (Table 1). Five of six patients died of complications of ECD 1 month to 16 years after the diagnosis of ECD was made. Patient 4 is alive 4 years after diagnosis but has severe respiratory compromise.

For three patients, the cause of death was related to pulmonary disease. Patient 1 was treated with corticosteroids and chloraminophene without much improvement. He had progressive lung dis- 
TABLE 2. Immunohistochemical Reactivities

\begin{tabular}{|c|c|c|c|c|c|c|c|c|c|}
\hline Patient & CD 68 & Lysozyme & Mac 387 & $\mathrm{CD} 45 \mathrm{RB}$ & S-100 protein & CD 1a & $\mathrm{CD} 21$ & Factor XIIIa & Other \\
\hline 1 & + & Weakly + & - & - & - & - & - & + & Vimentin + \\
\hline 2 & + & NT & NT & - & + & - & NT & + & $\begin{array}{l}\text { Factor VIII, CEA, } \\
\text { EMA, CD } 34-\end{array}$ \\
\hline 3 & + & Weakly + & - & - & - & - & - & + & - \\
\hline 4 & + & NT & NT & NT & - & - & - & + & HLA-DR - \\
\hline 5 & NV & NV & NV & NV & NV & NV & NV & NV & - \\
\hline 6 & + & + & NT & NT & + & - & - & + & - \\
\hline
\end{tabular}

NV, nonviable; NT, not tested.

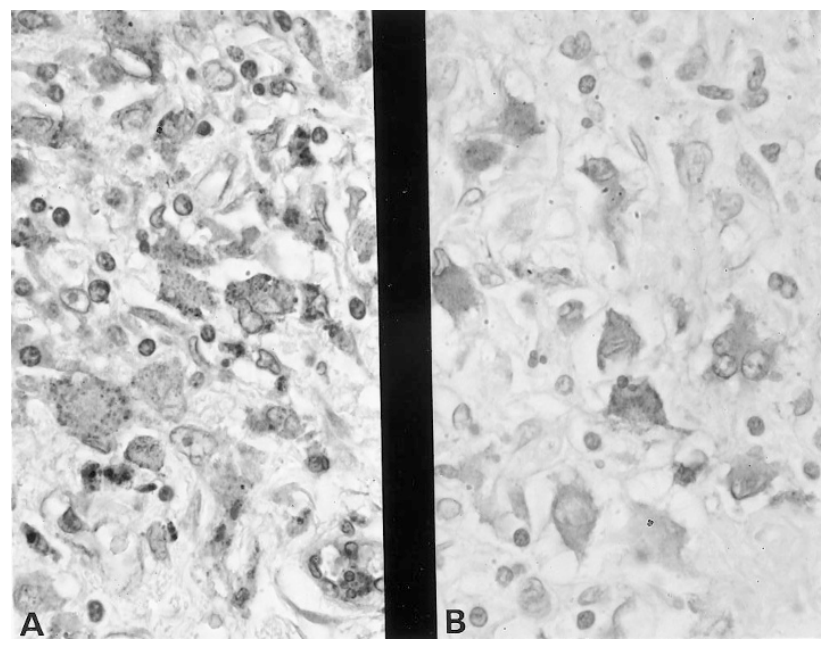

FIGURE 8. Patient 6 . Immunoperoxidase stains of pulmonary lesions. A, KP-1 (CD 68) $(600 \times)$. B, Factor XIIIa $(600 \times)$.

ease and osseous pain and died of cardiac and pulmonary failure 5 years after diagnosis. Patient 2 was admitted to the hospital with purulent bronchitis superimposed on his severe interstitial lung disease and a popliteal artery aneurysm. He underwent resection of the aneurysm and subsequently developed methicillin-resistant staphylococcal pneumonia and acute renal failure leading to death. Patient 6 was treated with corticosteroids, which resulted in clinical improvement but minimal radiographic change. His pulmonary disease continued to worsen, and he died of right-sided heart failure secondary to pulmonary fibrosis and pulmonary embolism 9 years after diagnosis. At autopsy, he had extensive pulmonary and pleural fibrosis. In addition, he had pericardial fibrosis, pericardial effusion $(500 \mathrm{~mL})$, cardiomegaly, right ventricular hypertrophy, and an acute pulmonary embolism partially obstructing the left pulmonary artery.

The cause of death in the remaining two patients was related to obstructive thoracic and abdominal disease. Patient 3 died of retroperitoneal fibrosis with consequent renal failure. Patient 5 died of a hemorrhagic cerebral vascular accident. At autopsy, there were extensive infiltrates of foamy histiocytes involving the retroperitoneum, pleura, pericardium, and aorta with nearly complete occlusion of the left carotid artery.

\section{DISCUSSION}

Patients with lung involvement by ECD typically present with progressive dyspnea over a period of months to years (4). On radiography, thoracic disease is characterized by nonspecific findings of diffuse interstitial and pleural thickening with or without effusion. CT scans typically show interlobular septal and pleural thickening. There may be associated patchy centrilobular ground glass opacities. The low-power histologic appearance of ECD reflects the CT findings (14). The histiocytic infiltrates are strikingly lymphangitic in distribution and therefore are seen in the visceral pleura, in interlobular septa, and around bronchovascular bundles (14). As emphasized by Chester (1), a proliferation of fibrous tissue accompanies the histiocytic infiltrates, which is typically most pronounced in the pleura and interlobular septa.

Immunophenotypically, the histiocytes are positive for CD68 and show variable staining with S-100 protein. Immunoreactivity for S-100 protein was observed in two of six cases in this study and, likewise, was variably reactive in four of five cases reported by Egan et al. (14). In contrast with Langerhans' cell histiocytosis, CDla was negative in each of our cases as well as in all of the cases of ECD reported to date. A novel finding in this study was strong Factor XIIIa immunoreactivity, which was observed in the lung sections and other involved sites. Factor XIIIa is positive in dermal dendritic cells, a term coined by Headington and Cerio (18). Factor XIIIa-positive dendritic cells are also found in other tissues, such as the gastrointestinal tract, bladder, kidney, and lung (19). It is interesting that in the lung, Factor XIIIa-positive cells are most prominent in the connective tissue around bronchioles and blood vessels and along interalveolar septa, a distribution similar to the pulmonary lesions of ECD (19).

The function of Factor XIIIa-positive histiocytes is not well characterized. It has been shown that they stimulate fibroblastic proliferation $(20,21)$, which may account for the fibrotic appearance of pulmonary ECD. In view of the perivascular location of Factor XIIIa-positive histiocytes in the skin and mucosa, some investigators have also postu- 
lated a role in immune regulation. Sertl et al. (22) described antigen- presenting cells, which lack Birbeck granules, in mouse lung parenchyma and visceral pleura. These seem to be similar in morphology and distribution to the Factor XIIIa histiocytes described by Derrick et al. (19).

The differential diagnosis of pulmonary involvement by ECD includes interstitial lung diseases and, in particular, usual interstitial pneumonitis (UIP) and various primary and secondary histiocytic disorders. Similar to ECD, UIP clinically presents as insidious progressive dyspnea in adult patients. Histologically, both disorders demonstrate prominent pleural and septal fibrosis on low-power examination; however, in ECD, there is geographic uniformity of the fibrosis in contrast to the mixture of fibroblastic foci and mature fibrosis with skip areas, characteristic of UIP. Histiocytic infiltrates distributed along the pleura, septa, and perivascular interstitium are the hallmark features of ECD. In advanced fibrotic lesions, the histiocytic proliferation may be difficult to appreciate without immunohistochemical studies. Other secondary histologic features commonly seen in UIP (smooth muscle hyperplasia, squamous metaplasia, and hypertensive vascular changes) have not been reported in ECD.

Another form of interstitial lung disease, characterized by histiocytic proliferation and fibrosis, is pulmonary Langerhans' cell histiocytosis (LCH). Radiographically, LCH shows a distinctive pattern of cysts and nodules seen on plain film and on high-resolution CT, which differs from the radiographic appearance of ECD. Histologically, the lesions of LCH are predominantly peribronchiolar in location in contrast to the angiocentric and pleural distribution of histiocytes of ECD. Langerhans' cells are characterized by prominent nuclear grooves and can be definitively identified by their strong staining with anti-CD1a antibodies and by the demonstration of Birbeck granules on ultrastructural analysis. The histiocytes of ECD have a round to oval shape without nuclear indentation, are nonreactive with CDla, and lack Birbeck granules. Distinction of ECD from pulmonary LCH is important because of the overall worse prognosis of the former. Nine of 18 previously reported ECD patients with lung involvement have died of disease at 3 weeks to 8 years after diagnosis (14). In contrast, pulmonary LCH, a smoking-related disorder, generally has an indolent course and may regress either spontaneously or after steroid therapy and/or cessation of smoking (23).

Sinus histiocytosis with massive lymphadenopathy, also known as Rosai-Dorfman disease (RDD), most commonly effects lymph nodes but rare cases have been reported in the lung. Clinically, most of the reported cases of RDD with lung involvement have presented as tumoral masses involving the large airways, and all have had evidence of nodal disease. Diffuse pulmonary involvement, which has been described in three cases of RDD, might be difficult to distinguish from ECD on the basis of morphology alone and may require correlation with the lymph node and bone findings (24). Infiltration and dilation of the perivascular lymphatic spaces by histiocytic infiltrates has been observed in pulmonary RDD, a feature that may be useful in distinguishing the two entities (25). The histiocytes in RDD have abundant foamy cytoplasm as in ECD but are distinguished by the presence of wellpreserved lymphocytes in their cytoplasm, a phenomenon known as emperipolesis. Unlike ECD, the histiocytes in RDD are consistently positive for S-100 protein. In addition, immunoreactivity for Factor XIIIa has been reported in only one unusual case of RDD limited to the skin (26).

Xanthoma disseminatum (XD) is composed of Factor XIIIa-positive histiocytes and may give a clinical presentation similar to ECD in that XD patients often have periorbital xanthomas and approximately $40 \%$ have diabetes insipidus (27). The diabetes insipidus in XD typically is mild and transitory, whereas that of ECD is persistent and progressive. $\mathrm{XD}$ patients are young at presentation (most are younger than 25 years) and have widespread cutaneous lesions typically involving the flexural areas. They often have mucosal involvement. Pharyngeal and laryngeal lesions are not uncommon, but involvement of the lower respiratory tract is rare and is characterized by thickening of the trachea and main bronchi (28). In addition, osseous lesions have been only rarely reported and are lytic in nature and para-articular in distribution (29).

Six percent of diabetic patients develop perivascular xanthogranulomatosis (30), which typically is asymptomatic and found only at autopsy. Additional considerations in the differential diagnosis of lung involvement by ECD were reviewed by Egan $e t$ al. (14) and include sarcoidosis, Gaucher's disease (31), Whipple's disease (32), and malacoplakia (33, $34)$.

In summary, ECD is a rare type of nonLangerhans' cell histiocytosis, which may cause progressive lung disease. Affected patients show characteristic radiologic and histologic findings, which need to be discriminated from other types of histiocytic disorders and interstitial lung disease. Although the exact origin of the ECD histiocyte is unclear, the results of this study suggest derivation from Factor XIIIa-positive dendritic cells.

Acknowledgments: The authors express their gratitude for the photographic assistance of Mr. Luther 
Duckett (medical photographer) and Ms. RobinAnne V. Ferris, M.F.S. (section chief) of the photography section, Armed Forces Institute of Pathology.

\section{REFERENCES}

1. Chester W. Uber lipoidgranulomatose. Virchows Arch Pathol Anat 1930;279:561-602.

2. Sorenson EW. Hyperlipemia. A report of an unusual case complicated by bone lesions, macrocytic anaemia and leukemoid bone marrow. Acta Med Scan 1964;175(2):207-14.

3. Jaffe HL. Gaucher's disease and certain other inborn metabolic disorders: lipid (cholesterol) granulomatosis. In: Jaffe HL, editor. Metabolic, degenerative and inflammatory diseases of bones and joints. Philadelphia: Lea \& Febiger; 1972. p. $535-41$.

4. Veyssier-Belot C, Cacoub P, Caparros-Lefebvre D, Wechsler J, Brun B, Remy M, et al. Erdheim-Chester disease. Clinical and radiologic characteristics of 59 cases. Medicine 1996; 75(3):157-69.

5. Elian M, Bornstein B, Matz S, Askenasy HM, Sandbank U, Tiqua P. Neurological manifestations of general xanthomatosis. Hand-Schuller-Christian disease. Arch Neurol 1969; 21(2):115-20.

6. Freyschmidt J, Ostertag H, Lang W. Case report 365: Erdheim-Chester disease. Skeletal Radiol 1986;15(4):316-22.

7. Kujat C, Martin J, Puschel W. [Erdheim-Chester disease]. Radiologe 1991;31(6):297-306.

8. Palmer FJ, Talley NJ. Erdheim-Chester disease with bilateral exophthalmus and liver cell adenoma. Australas Radiol 1984; 28(4):305-10.

9. Resnick D, Greenway G, Genant H, Brower A, Haghighi P, Emmett M. Erdheim-Chester disease. Radiology 1982;142(2): 289-95.

10. Sherman JL, Citrin C, Johns T, Black J. Erdheim-Chester disease: computed tomography in two cases. Am J Neuroradiol 1985;6(3):444-5.

11. Fink MG, Levinson DJ, Brown NL, Sreekanth S, Sobel GW. Erdheim-Chester disease. Case report with autopsy findings. Arch Pathol Lab Med 1991;115(6):619-23.

12. Kambouchner M, Colby TV, Domenge C, Battesti JP, Soler P, Tazi A. Erdheim-Chester disease with prominent pulmonary involvement associated with eosinophilic granuloma of mandibular bone. Histopathology 1997;30(4):353-8.

13. Madroszyk A, Wallaert B, Remy J, Gosselin B, Caparros D, Tonnel AB. Pneumopathie interstitielle diffuse revelant une maladie d'Erdheim-Chester [Diffuse interstitial pneumonia revealing Erdheim-Chester's disease]. Rev Mal Respir 1994;11(3): 304-7.

14. Egan AJM, Boardman L, Tazelaar H, Swenson S, Jett J, Yousem S, et al. Erdheim-Chester disease. Clinical, radiologic, and histopathologic findings in five patients with interstitial lung disease. Am J Surg Pathol 1999;23(1):17-26.

15. Devouassoux G, Lantuejoul S, Chatelain P, Brambilla E, Brambilla C. Erdheim-Chester disease: a primary macrophage cell disorder. Am J Respir Crit Care Med 1998;157(2): $650-3$.
16. Alper MG, Zimmerman LE, Piana FG. Orbital manifestations of Erdheim-Chester disease. Trans Am Ophthalmol Soc 1983;81:64-85.

17. Hsu SM, Raine L. Protein A, avidin, and biotin in immunohistochemistry. J Histochem Cytochem 1981;29(11):1349-53.

18. Headington J, Cerio R. Dendritic cells and the dermis: 1990. Am J Dermatopathol 1990;12(3):217-20.

19. Derrick E, Barker J, Khan A, Price M, MacDonald D. The tissue distribution of factor XIIIa positive cells. Histopathology 1993;22:157-62.

20. Reid MB, Gray C, Fear JD, Bird CC. Immunohistological demonstration of factors XIIIa and XIIIs in reactive and neoplastic fibroblastic and fibro-histiocytic lesions. Histopathology 1986;10(11):1171-8.

21. Silverman JS, Tamsen A. Mammary fibroadenoma and some phyllodes tumour stroma are composed of CD34+ fibroblasts and factor XIIIa+ dendrophages. Histopathology 1996;29(5):411-9.

22. Sertl K, Takemura T, Tschachler E, Ferrans VJ, Kaliner MA, Shevach EM. Dendritic cells with antigen-presenting capability reside in airway epithelium, lung parenchyma, and visceral pleura. J Exp Med 1986;163(2):436-51.

23. Travis WD, Borok Z, Roum JH, Zhang J, Feuerstein I, Ferrans VJ, et al. Pulmonary Langerhans cell granulomatosis (histiocytosis X). A clinicopathologic study of 48 cases. Am J Surg Pathol 1993;17:971-86.

24. Foucar E, Rosai J, Dorfman RF. Sinus histiocytosis with massive lymphadenopathy (Rosai-Dorfman disease): review of the entity. Semin Diagn Pathol 1990;7(1):19-73.

25. Wright D, Richards D. Sinus histiocytosis with massive lymphadenopathy (Rosai-Dorfman disease): report of a case with widespread nodal and extra nodal dissemination. Histopathology 1981;5:697-709.

26. Perrin C, Michiels JF, Lacour JP, Chagnon A, Fuzibet JG. Sinus histiocytosis (Rosai-Dorfman disease) clinically limited to the skin. An immunohistochemical and ultrastructural study. J Cutan Pathol 1993;20:368-74.

27. Szekeres E, Tiba A, Korom I. Xanthoma disseminatum: a rare condition with non-X, non-lipid cutaneous histiocytopathy. Dermatol Surg Oncol 1988;14:1021-4.

28. Moloney J. Xanthoma disseminatum: its otolaryngological manifestations. J Laryngol Otol 1979;93(2):201-10.

29. Mishkel M, Cockshott W, Nazir D, Rosenthal D, Spaulding W, Wynn-Williams A. Xanthoma disseminatum. Arch Dermatol 1977;113(8):1094-100.

30. Reinila A. Perivascular xanthogranulomatosis in the lungs of diabetic patients. Arch Pathol Lab Med 1976;100(10):542-3.

31. Schneider EL, Epstein CJ, Kaback MJ, Brandes D. Severe pulmonary involvement in adult Gaucher's disease. Report of three cases and review of the literature. Am J Med 1977; 63(3):475-80.

32. Kelly CA, Egan M, Rawlinson J. Whipple's disease presenting with lung involvement. Thorax 1996;51(3):343-4.

33. Schwartz DA, Ogden PO, Blumberg HM, Honig E. Pulmonary malakoplakia in a patient with the acquired immunodeficiency syndrome. Differential diagnostic considerations. Arch Pathol Lab Med 1990;114(12):1267-72.

34. Hodder RV, St George-Hyslop P, Chalvardjian A, Bear RA, Thomas P. Pulmonary malakoplakia. Thorax 1984;39 (1):70-1. 